\title{
Epidemiological and genetic study in 207 cases of oral clefts in Alsace, north-eastern France
}

\author{
C Stoll, Y Alembik, B Dott, M P Roth
}

\begin{abstract}
The epidemiology of oral clefts was studied in the geographical area covered by our registry of congenital malformations. For each of the 207 new cases studied during the period 1979 to 1987 , more than 50 factors were compared in probands and controls. The incidence of oral clefts was 1.75 per 1000, with cleft lip/palate $(C L(P)) \quad 0.98$ and cleft palate only (CP) 0.77 per 1000 . A total of $8.2 \%$ of cleft cases were stillbirths and $5.3 \%$ were induced abortions. The more common types of associated malformations in the 76 affected cases (36.7\%) with at least one anomaly other than oral cleft were neural tube defects and skeletal malformations. At birth, infants with oral clefts and other malformations were smaller, weighed less, and their head circumference was lower than in controls. Placental weight was also lower than in controls. Pregnancies with oral clefts were more often complicated by threatened abortion, polyhydramnios, and arterial hypertension. There was a significant association between clefting and consanguinity; heritability of $C L(P)$ was $81 \%$ and first degree relatives of probands had more than three times the prevalence of noncleft malformations as controls. These results are of relevance to genetic counselling.
\end{abstract}

The epidemiology and genetics of cleft lip with or without cleft palate $(\mathrm{CL}(\mathrm{P}))$ and isolated cleft palate (CP) have been studied in various countries by many investigators. $^{1-12}$ Despite the large mass of data available, the mode of inheritance and the role of environmental factors are not yet entirely clear. These malformations may be part of genetic syndromes with Mendelian inheritance, of other recognised syndromes, or of unclassified multiple malformations. After removal of these syndromic cases, which represent a

Institut de Puériculture, Centre Hospitalo-Universitaire, 23 rue de la Porte de l'Hôpital, 67091 Strasbourg Cédex, France.

C Stoll, Y Alembik, B Dott, M P Roth

Correspondence to Professor Stoll.

Received for publication 15 May 1990

Revised version accepted for publication 15 October 1990. small proportion of clefts, there remain the isolated cases, thought to be the consequence of multifactorial inheritance. ${ }^{10}$ It is generally accepted that $\mathrm{CL}(\mathrm{P})$ and $\mathrm{CP}$ are developmentally and genetically different and that hereditary factors are somewhat more important in $\mathrm{CP}$ than in CL(P). ${ }^{113-15}$ However, Chung et $a l^{816}$ and Marazita et al, ${ }^{17}$ using complex segregation analysis, could not discriminate between single locus and polygenic inheritance.

We present the results of a study undertaken to assess the epidemiology and the recurrence rates of clefts in families of affected children.

\section{Material and methods}

The material for this study came from 118265 consecutive births of known outcome, including 814 stillborn babies, registered in our registry of congenital malformations, which covers 11 maternity hospitals, for the period 1 January 1979 to 31 December 1987. The region of investigation was the city of Strasbourg, France (an urban area) and the area defined by the 'Departement du Bas-Rhin' in which Strasbourg is situated (a rural area). All newborn babies were registered within the first eight days after birth, as were all fetuses with a minimum age of 20 weeks. No delivery took place at home. ${ }^{18}$ When a suspected or a confirmed case was notified, the requested information was checked by a doctor from available records, including prenatal consultation records, maternity files, neonatal unit files, necropsy reports, outpatient clinic files, and paediatric and surgical files.

For each infant with a cleft a complete description was available, including photographs, karyotype, and radiographs for children with syndromes and multiple malformations. Clefts were subdivided into two groups: 'isolated' when only $\mathrm{CL}(\mathrm{P})$ or $\mathrm{CP}$ were present and 'associated' when additional malformations were found. Infants with Pierre-Robin sequence were classified in the group CP with additional malformations.

For each case more than 50 factors contained in the registration forms were studied, including parity and previous pregnancies, parental age, area of residence, education, ethnic origin, length, head circumference, and weight at birth, genetic factors (consanguinity of parents, inheritance, cytogenetics, occurrence in 
twins), environmental factors, seasonality, and pregnancy. Follow up information was obtained through the paediatric surgeon and the physician in charge of the infant's care.

The control group comprised normal children born after each cleft case in the same maternity hospital and matched for sex. For seasonality studies, the monthly occurrences of all normal births from 1979 to 1987 were chosen as control rates. To determine sex ratios the normal newborn population was used as a control group.

Statistical analysis was performed using the Statistical Analysis System (SAS) procedure software package. ${ }^{19}$ Comparison of frequencies was by the $\chi^{2}$ test with Yates's correction where appropriate. When numbers were very small Fisher's exact test was used and $t$ tests were used to compare means. Multiple linear regression and the spectra procedure ${ }^{1920}$ were used for seasonality studies. For detection of time clusters, observed/expected ratio ${ }^{21}$ and scan techniques $^{22}$ were used. For monitoring, the cumulative sum technique ${ }^{23} 24$ was used. Odds ratio values were calculated according to the SAS procedure. ${ }^{19}$

\section{Results}

During the nine year study period, 207 cases of $\mathrm{CL}(\mathrm{P})$ and $C P$ were detected; 179 were livebirths $(86.5 \%), 17$ $(8 \cdot 2 \%)$ were stillbirths or late spontaneous abortions, and in 11 cases $(5 \cdot 3 \%)$ pregnancies had been terminated after prenatal diagnosis of associated malformations.

The incidence of clefts and associated malformations and the distribution of patients by type and side of cleft are shown in tables 1 to 3 .

Table 4 shows the distribution of malformations associated with clefts, excluding chromosomal abnormalities. The expected number of non-cleft malformations in cleft children with another malformation of a specific type was calculated from the frequency of that specific malformation in multimalformed infants without clefts registered during the period 1979 to 1987.

The male:female ratio for all infants with clefts was 113:94=1.20 (controls 1.07, not significant (NS)). For $\mathrm{CL}(\mathrm{P})$ and for $\mathrm{CP}$ the male:female ratios were
Table 2 Distribution of patients by type of cleft.

\begin{tabular}{lcccr}
\hline & Males & Females & $\begin{array}{c}\text { Total } \\
\text { No }\end{array}$ & $\%$ \\
\hline CL & 32 & 14 & 46 & $22 \cdot 2$ \\
CLP & 44 & 26 & 70 & $33 \cdot 8$ \\
CP & 37 & 54 & 91 & $44 \cdot 0$ \\
Total & 113 & 94 & 207 & $100 \cdot 0$ \\
\hline
\end{tabular}

Table 3 Distribution of $C L(P)$ cases by side and sex.

\begin{tabular}{lrrr}
\hline & Sex & No & \multicolumn{1}{c}{$\%$} \\
\hline Unilateral & M & 25 & $21 \cdot 6$ \\
Right & F & 16 & $13 \cdot 8$ \\
Left & M & 33 & $28 \cdot 4$ \\
Bilateral & F & 25 & $21 \cdot 6$ \\
Total & M & 10 & $8 \cdot 6$ \\
& F & 7 & $6 \cdot 0$ \\
\hline
\end{tabular}

respectively $76: 40=1.90(p<0.05)$ and $37: 54=0.69$ (NS). No statistically significant difference between cleft and control cases was found for maternal age, paternal age, parity, previous pregnancy, area of residence, education, or ethnic origin.

Analysis of weight, length, and head circumference at birth and weight of placenta was carried out after standardisation for sex and gestational age for all infants with clefts (infants with isolated clefts and infants with associated clefts). No statistically significant difference was shown between either of the first two groups and controls. By contrast these factors were significantly decreased in the associated group compared to the controls $(p<0.01)$.

\section{FACTORS ASSOCIATED WITH CLEFTS \\ Genetic factors}

Consanguinity of parents. There were eight cases of parental consanguinity (3.9\%), two second cousins once removed, four first cousins once removed, and two first cousins (controls $0.9 \%, \mathrm{p}<0.05$ ).

Occurrence in twins. Seven pairs of twins and one set of triplets were observed. Only one twin sib was affected in a pair of dizygotic twins.

Table 1 Incidence of clefts and associated malformations.

\begin{tabular}{|c|c|c|c|c|c|c|c|}
\hline & \multicolumn{3}{|c|}{ No (\%) } & \multicolumn{4}{|c|}{ Incidence per 10000 births } \\
\hline & $\mathrm{CL}(\mathbf{P})$ & $\mathrm{CP}$ & Total & $\operatorname{CL}(\mathbf{P})$ & $\mathrm{CP}$ & To & tal \\
\hline Isolated & $83(40 \cdot 1)$ & $48(23 \cdot 2)$ & $131(63 \cdot 3)$ & $7 \cdot 0$ & $\begin{array}{l}4 \cdot 1 \\
3.6\end{array}$ & $11 \cdot 1$ & \\
\hline $\begin{array}{l}\text { Associated } \\
\text { Chromosomal abnormalities } \\
\text { Non-chromosomal }\end{array}$ & $33 \begin{array}{c}(15 \cdot 9) \\
10\end{array}$ & $\begin{array}{c}43(20 \cdot 8) \\
4\end{array}$ & $\begin{array}{l}76(36 \cdot 7) \\
14(6 \cdot 8)\end{array}$ & $\begin{array}{ll}2.8 & 0.8\end{array}$ & ${ }^{3.6} 0.3$ & $6 \cdot 4$ & $1 \cdot 2$ \\
\hline $\begin{array}{l}\text { recognised syndromes } \\
\text { Multiply malformed }\end{array}$ & $\begin{array}{r}8 \\
15\end{array}$ & $\begin{array}{l}19 \\
20\end{array}$ & $\begin{array}{l}27(13 \cdot 0) \\
35(9 \cdot 6)\end{array}$ & $\begin{array}{l}0.6 \\
1.2\end{array}$ & $\begin{array}{l}1.6 \\
1.7\end{array}$ & & $\begin{array}{l}2 \cdot 3 \\
2 \cdot 9\end{array}$ \\
\hline Total & 116 & 91 & 207 & $9 \cdot 8$ & $7 \cdot 7$ & $17 \cdot 5$ & \\
\hline
\end{tabular}


Table 4 Associated malformations observed in infants with clefts* and expected number of non-cleft malformations by standardisation.

\begin{tabular}{|c|c|c|c|c|c|c|}
\hline \multirow[b]{3}{*}{ Anomalies } & \multicolumn{4}{|c|}{ Observed } & \multirow{2}{*}{\multicolumn{2}{|c|}{ Expected by standardisation (\%) }} \\
\hline & \multicolumn{2}{|c|}{$\mathrm{CL}(\mathbf{P})$} & \multicolumn{2}{|c|}{$\mathbf{C P}$} & & \\
\hline & No & $\%$ & No & $\%$ & $\mathrm{CL}(\mathbf{P})$ & $\mathbf{C P}$ \\
\hline $\begin{array}{l}\text { Neural tube defects } \\
\text { Hydrocephalus } \\
\text { Encephalocele } \\
\text { Anencephaly } \\
\text { Other }\end{array}$ & $\begin{array}{l}9^{16} \\
4 \\
1 \\
2\end{array}$ & $31 \cdot 4$ & $2^{2}$ & $3 \cdot 3$ & $\begin{array}{l}1.6 \\
0.2 \\
0.3\end{array}$ & $\begin{array}{l}3 \cdot 1 \\
0.3 \\
0.6\end{array}$ \\
\hline $\begin{array}{l}\text { Skeletal } \\
\text { Club foot } \\
\text { Polydactyly } \\
\text { Syndactyly } \\
\text { Reduction limb defects } \\
\text { Other }\end{array}$ & $\begin{array}{ll}5^{12} \\
3 & \\
1 & \\
1 & \\
1 & \end{array}$ & $23 \cdot 5$ & $\begin{array}{l}3 \\
3 \\
3 \\
6 \\
3\end{array}$ & $25 \cdot 0$ & $\begin{array}{l}3 \cdot 6 \\
1.5 \\
1 \cdot 3 \\
0 \cdot 8\end{array}$ & $\begin{array}{l}2 \cdot 8 \\
2 \cdot 2 \\
2 \cdot 4 \\
6 \cdot 1\end{array}$ \\
\hline $\begin{array}{l}\text { Cardiac } \\
\text { Ventricular septal defect } \\
\text { Atrial septal defect } \\
\text { Other }\end{array}$ & $\begin{array}{ll}1 & 2 \\
1 & \end{array}$ & 3.9 & $\begin{array}{ll}3 & 9 \\
4 & \\
2 & \end{array}$ & $15 \cdot 0$ & $\begin{array}{l}3.3 \\
1.8\end{array}$ & $\begin{array}{l}6 \cdot 3 \\
3 \cdot 4\end{array}$ \\
\hline $\begin{array}{l}\text { Gastrointestinal system } \\
\text { Common mesenter } \\
\text { Other }\end{array}$ & $\begin{array}{ll}1 \\
2\end{array}$ & 3.9 & $\begin{array}{ll}3 & 4 \\
1 & \end{array}$ & $6 \cdot 7$ & $1 \cdot 8$ & $3 \cdot 5$ \\
\hline $\begin{array}{l}\text { Urinary system } \\
\text { Polycystic kidney } \\
\text { Other }\end{array}$ & $\begin{array}{l}3 \\
3^{9}\end{array}$ & $17 \cdot 6$ & $\frac{1}{2}^{3}$ & $5 \cdot 0$ & 1.9 & $1 \cdot 5$ \\
\hline Genital & 1 & $2 \cdot 0$ & 2 & $3 \cdot 3$ & & \\
\hline Diaphragmatic hernia & & & 2 & $3 \cdot 3$ & $1 \cdot 5$ & $3 \cdot 6$ \\
\hline $\begin{array}{l}\text { Head and face } \\
\text { Microcephaly } \\
\text { Microphthalmia } \\
\text { Facial dysmorphism } \\
\text { Micrognathia }\end{array}$ & $\begin{array}{ll} & 7 \\
1 & \\
3 & \\
3 & \end{array}$ & $13 \cdot 7$ & $\begin{array}{r}22 \\
3 \\
2 \\
15\end{array}$ & $36 \cdot 7$ & $\begin{array}{l}0 \cdot 8 \\
0 \cdot 6 \\
5 \cdot 2\end{array}$ & $\begin{array}{r}1 \cdot 6 \\
1 \cdot 0 \\
3 \cdot 0 \\
19 \cdot 0\end{array}$ \\
\hline $\begin{array}{l}\text { Ear anomalies } \\
\text { Total }\end{array}$ & 51 & 3.9 & $\begin{array}{r}1 \\
60\end{array}$ & $1 \cdot 7$ & $2 \cdot 1$ & $1 \cdot 3$ \\
\hline
\end{tabular}

${ }^{*}$ Some patients had malformations in more than one additional system.

Other relatives. Nine mothers, seven fathers, and 11 sibs had the same non-Mendelian cleft anomaly as the proband, eight second degree relatives had a cleft (five on the maternal side and three on the paternal side), while 10 mothers, two fathers, and 11 other first degree relatives had non-cleft congenital malformations $(11 \cdot 1 \%)$ (controls $3.3 \%, \mathrm{p}<0.01$ ).

Inheritance. An inherited Mendelian condition was present in seven cases: three Meckel's syndrome, two COFS syndrome, one TAR syndrome, and one orofaciodigital syndrome.

Recognised non-chromosomal syndromes. Four infants had non-chromosomal syndromes: one CHARGE association, one VATER association, one fetal alcoholism syndrome, and one Seckel's syndrome.

Cytogenetics. Karyotypes were obtained in 95 of the cases $(45 \cdot 9 \%)$, of which all but 14 were $46, \mathrm{XX}$ or XY. Ten of the abnormal karyotypes were in the CL(P) infants and included five trisomy 13 , two trisomy 18 , one inversion with deletion $5 \mathrm{q}$, one inversion with deletion $4 \mathrm{q}$, and one Klinefelter's syndrome. The remaining four abnormal karyotypes were in CP children and included one trisomy 13, one Turner's syndrome, one extra small unidentified metacentric chromosome, and one duplication 18q.

\section{Environmental factors}

Fifty two mothers of cleft infants were smokers $(25 \cdot 1 \%)$ (controls $21 \cdot 2 \%$, NS). The number of mothers not exposed to industrial agents (unemployed, housewife, clerk, professional, and managerial) was $165(79 \cdot 7 \%)$. The number of mothers exposed to industrial agents (unskilled, semiskilled, and skilled workers) was $42(20.3 \%)$ (controls: not exposed $74.9 \%$, exposed $25 \cdot 1 \%$ (NS)). A total of $107(51 \cdot 7 \%$ ) of the fathers was exposed to industrial agents during work (controls $52 \cdot 6 \%$, NS).

Seasonality. No seasonal variation in birth incidence could be shown by comparison with normal newborn babies in the area under study during the same period of time.

Pregnancy. Twenty-two mothers (10.6\%) took contraceptive pills during the three months before pregnancy 
and four had used an IUD (controls $11 \cdot 1 \%$ (NS) and four respectively).

During pregnancy $10 \cdot 1 \%$ of the women had had threatened abortions, $10.6 \%$ hydramnios, and $2.9 \%$ oligohydramnios (controls $4.3 \% \quad(p=0.01), 3.8 \%$ $(p=0.006)$, and $1.3 \%$ (NS) respectively); $3.3 \%$ of the mothers of the cleft cases were diabetic (IDDM), $2.9 \%$ were epileptic, and $8.7 \%$ had arterial hypertension (controls $2 \cdot 4 \%$ (NS), $0.9 \%(\mathrm{NS}$ ), and $3.4 \%$ $(p=0.01)$ respectively); $4.3 \%$ had had $x$ rays, $7 \cdot 7 \%$ fever, and $7 \cdot 7 \%$ influenza (controls $3 \cdot 4 \%, 8 \cdot 2 \%$, and $6.7 \%$ (NS) respectively); $42.5 \%$ took medication (controls $38.6 \%$ (NS)). Five mothers out of 131 infants with isolated $C L(P)$ and $C P$ were epileptic (controls 1 out of 131). Only one mother out of 76 children with associated $\mathrm{CL}(\mathrm{P})$ or $\mathrm{CP}$ was epileptic (controls 1 out of 76$)$. In $11(5 \cdot 3 \%)$ of mothers prenatal diagnosis was performed after discovery of fetal malformations associated with $\mathrm{CL}(\mathrm{P})$ or $\mathrm{CP}$ and was followed by termination of pregnancy.

Risk factors were studied for total clefts and for CL(P) and CP separately. Odds ratios were not significant for diabetes, radiographs, epilepsy, fever, influenza, medication, cigarette smoking, occupational exposure of mother or father, maternal age, and paternal age.

Heritability in sibs. The 83 isolated CL(P) cases had a total of 51 sibs. Two of these sibs had CL(P) (3.9\%). The general population incidence used for calculating the heritability of $\mathrm{CL}(\mathrm{P})$ was $\mathrm{q}=0.0701 \% .{ }^{12}$ Assuming multifactorial inheritance, the estimated heritability from first degree relatives is $0.81( \pm 0 \cdot 16)$ according to the method of Falconer. ${ }^{25}$ Only one affected sib was found among CP cases.

\section{Discussion}

The population incidence of $\mathrm{CL}(\mathrm{P})$ and $\mathrm{CP}$ in this series is comparable to that in a previous French study, ${ }^{10}$ which estimated the frequencies of $\mathrm{CL}(\mathrm{P})$ and isolated $\mathrm{CP}$ as $0.082 \%$ and $0.035 \%$ respectively, after exclusion of malformation syndromes. The prevalence of all clefts in our population (1.75 per 1000 ) is comparable to that in Denmark (1.89 per 1000 ) and in the other Scandinavian countries, ${ }^{11}$ higher than in Emilia Romagna, Italy (1.33 per 1000 or $0.075 \%$ for $C L(P)$ and $0.058 \%$ for $C P)^{12}$ where a similar population was under study, and higher than in most of the other registries. ${ }^{26}{ }^{27}$ Thirty-six percent (76/207) of facial cleft malformations were associated with at least one other major malformation compared with $33 \%$ in the study of Calzolari et al, ${ }^{12} 22 \%$ in Denmark, ${ }^{28}$ and $63 \cdot 4 \%$ in New York. ${ }^{29}$ These associated anomalies were more common in $\mathrm{CP}$ $(47 \cdot 2 \%)$ than in CL(P) $(28.4 \%)$ as in the studies of Welch and Hunter ${ }^{9}$ and of Calzolari et al. ${ }^{12}$

The distribution of the total sample of our 207 patients within the three main types of clefts was
$22 \cdot 2 \%$ for $\mathrm{CL}, 33.8 \%$ for $\mathrm{CL}(\mathrm{P})$, and $44.0 \%$ for $\mathrm{CP}$, which is higher for CP and lower for CL than in the Danish population. ${ }^{11}$

No significant trend in cleft incidence was detected over time and there were no time clusters and no urban-rural differences.

The karyotype was abnormal in 14 cases $(6.7 \%)$ which is twice that reported by Calzolari et al. ${ }^{12}$ The more common abnormalities were trisomies 13 and 18 and structural chromosomal anomalies. The higher frequency of chromosomal anomalies in our study compared to that of Calzolari et $\mathrm{al}^{12}$ may be explained by the fact that karyotypes were obtained in $45.9 \%$ of our cases and in only $21.5 \%$ of their cases. All our cleft cases with chromosomal anomalies had additional malformations. Therefore, in our opinion, the karyotype should be studied in the patients with associated clefts unless a recognised non-chromosomal syndrome is present.

Several specific malformations appeared to be more common among our multiply malformed infants with $\mathrm{CL}(\mathrm{P})$ than among such infants without $\mathrm{CL}(\mathrm{P})$ (table 4), especially neural tube defects and microphthalmia, whereas other malformations, such as ventricular septal defect, were less common.

Infants with clefts and additional malformations were of lower birth weight, lower birth length, had a smaller head circumference, and lower placental weight than controls. It seems unlikely that clefts are directly responsible for poor intrauterine growth as our study showed that patients with isolated clefts have no intrauterine growth retardation. Lower birth weight of infants with clefts was also found by Calzolari et $a l^{12}$ and Saxen. ${ }^{30}$

Pregnancies of mothers with infants with clefts were more often complicated by threatened abortions, hydramnios, and arterial hypertension. Saxen ${ }^{30}$ found an increase of pregnancies complicated by threatened abortion in her series. Hydramnios and arterial hypertension may be also considered to be risk factors. As in the study of Bonaiti $e t a l,{ }^{10}$ there was an increased frequency of epileptic mothers of isolated $\mathrm{CL}(\mathrm{P})$ and $\mathrm{CP}$ in our cases compared to the control group, but we have too few cases to draw a definitive conclusion.

As in the other series, ${ }^{9} 123132$ this study found a significant predominance of males with $\mathrm{CL}(\mathrm{P})$ and of females with CP.

Contrary to the previous studies which found no significant association between consanguinity and clefts, ${ }^{7912}$ we found a significant association between these two factors. This cannot be explained by ascertainment bias owing to inherited syndromes as the parents of the cases with the syndromes were not related. A more reliable conclusion is that, as for urinary tract malformations for instance, a multifactorial aetiology must be involved depending upon genetic predisposition with a recessive component and 
upon environmental factors. The risk of recurrence for $\mathrm{CL}(\mathrm{P})$ in first degree relatives was $3.9 \%$ and heritability from first degree relatives was $0 \cdot 81$. These results are in accordance with those of Welch and Hunter, ${ }^{9}$ Tolarova, ${ }^{33}$ Tenconi et $a l,{ }^{3}$ and Calzolari $e t$ $a l .{ }^{12}$ Theoretical recurrence risks for $\mathrm{CL}(\mathrm{P})$ were estimated by Tenconi et al. ${ }^{3}$ Non-cleft congenital malformations were present in $11.1 \%$ of first degree relatives of our cases, which is three times more than in the controls. Therefore, for genetic counselling, not only the recurrence risk of $\mathrm{CL}(\mathrm{P})$ has to be taken into consideration but also the risk of non-cleft congenital malformations in first degree relatives. If parents of children with $\mathrm{CL}(\mathrm{P})$ want to have other children they have to be aware that the risk of congenital malformations is higher than in the general population. Ultrasound examination for the detection of non-cleft malformations should be offered in subsequent pregnancies.

1 Fogh-Andersen P. Inheritance of harelip and cleft palate. Copenhagen: Busck, 1942

2 Kobayasi Y. A genetic study of harelip and cleft palate. $\mathcal{J p n} \mathcal{F}$ Hum Genet 1958;3:73-107.

3 Tenconi $R$, Clementi $M$, Turolla $L$. Theoretical recurrence risks for cleft lip derived from a population of consecutive newborns. 7 Med Genet 1988;25:243-6.

4 Woolf CM. Congenital cleft lip: a genetic study of 496 propositi. f Med Genet 1971;8:65-83.

5 Carter $\mathrm{CO}$. The inheritance of common congenital malformations. In: Steinberg AG, Bearn AG, eds. Progress in medical genetics. Vol 4. New York: Grune and Stratton, 1965:59-74.

6 Fujino H, Tashiro H, Sanui Y, et al. Empirical genetic risk among offspring of cleft lip and cleft palate patients. $\mathcal{F p n ~} \mathcal{F ~ H u m}$ Genet 1967;12:62-8.

7 Czeizel A, Tusnady G. A family study of cleft lip with or without cleft palate and posterior cleft palate in Hungary. Hum Hered 1972;22:405-16.

8 Chung CS, Ching GHS, Morton NE. A genetic study of cleft lip and palate in Hawaii. II. Complex segregation analysis and genetic risks. Am $\mathcal{F}$ Hum Genet 1974;26:177-88.

9 Welch J, Hunter AGW. An epidemiological study of facial clefting in Manitoba. 7 Med Genet 1980;17:127-32.

10 Bonaiti C, Briard ML, Feingold J, et al. An epidemiological and genetic study of facial clefting in France. I. Epidemiology and frequency in relatives. $\mathcal{F}$ Med Genet 1982;19:8-15.

11 Jensen BL, Kreiburg S, Dahl E, et al. Cleft lip and palate in
Denmark, 1976-1981: epidemiology, variability and early somatic development. Cleft Palate 7 1988;25:267-9.

12 Calzolari E, Milan M, Cavazzuti GB, et al. Epidemiological and genetic study of 200 cases of oral cleft in Emilia Romagna Region of Northern Italy. Teratology 1988;38:559-64.

13 Fraser FC. The genetics of cleft lip and cleft palate. Am $7 \mathrm{Hum}$ Genet 1970;22:336-52.

14 Fogh-Andersen P. Genetic and non-genetic factors in the aetiology of facial clefts. Scand f Plast Reconstr Surg 1967;1 22-9.

15 Woolf CM, Woolf RM, Broadbent TR. A genetic study of cleft lip and palate in Utah. Am F Hum Genet 1963;102:853-7.

16 Chung CS, Rao DC, Ching GHS. Population and family studies of cleft lip and palate. In: Melnick M, Bixler D, Shields ED, eds. Etiology of cleft lip and cleft palate. Progress in clinical and biological research, vol 46. New York: Alan R Liss, 1980.

17 Marazita ML, Goldstein AM, Smalley SL, et al. Cleft lip with or without cleft palate: reanalysis of a three generation family study from England. Genet Epidemiol 1986;3:335-42.

18 Stoll C, Roth MP, Dott B, et al. Etude des malformations congénitales dans le Nord de l'Alsace. Med Hygiène 1984;42: 505-12.

19 SAS user's guide. Statistics. Cary, NC: SAS Institute, 1988.

20 Fuller WA. Introduction to statistical time series. New York: John Wiley, 1986.

21 Weatherall JAC, Haskey JC. Surveillance of malformations. $\mathrm{Br}$ Med Bull 1976;32:39-44.

22 Wallenstein S. A test for detection of clustering over time. $A m \mathcal{F}$ Epidemiol 1980;111:367-72.

23 Woodward RH, Goldsmith PL. Cumulative sum techniques. Edinburgh: Oliver \& Boyd, 1964.

24 Barbujani G. A review of statistical methods for continuous monitoring of malformation frequencies. Eur $\mathcal{f}$ Epidemio 1987;3:67-77.

25 Falconer DS. The inheritance of liability to certain diseases, estimated from the incidence among relatives. Ann Hum Genet 1965;29:51-76.

26 De Wals P, Lechat MF. Surveillance of congenital anomalies. Years 1980-1984. Eurocat Report 2. Department of Epidemiology. Catholic University of Louvain, Bruxelles, 1987.

27 International Clearinghouse for Birth Defects Monitoring Systems. Annual Report, 1985.

28 Bixler D. Genetics and clefting. Cleft Palate J 1981;18:10-8.

29 Sphrintzen RJ, Siegel-Sadewitz VL, Amato J, et al. Anomalies associated with cleft lip, cleft palate or both. Am $\mathcal{F}$ Med Genet 1985;20:585-91.

30 Saxen I. Etiological variables in oral clefts. In: Proceedings of the Finnish Dental Society Suoman Hammaslaakariseuran Toimituksia (suppl) vol 3. Helsinki: Forssaw Kiriapaino, 1975:71.

31 Sayetta RB, Weinrich MC, Coston GN. Incidence and prevalence of cleft lip and palate: what we think we know. Cleft Palate $\mathcal{f}$ 1989;26:242-7.

32 Czeizel A, Tusnady G. Aetiological studies of isolated common congenital abnormalities in Hungary. Budapest: Akademia Kiado, 1984.

33 Tolarova $M$. Genetic investigation of cleft lip with or without cleft palate. A three generation family study of 578 pedigrees. $7 \mathrm{Med}$ Genet 1985;22:137A. 